\title{
Sensing of polymeric sensor-based rhodamine B derivative for metal cations in complete aqueous solution
}

\author{
TONG-MOU GENG ${ }^{1, *}$, XIE WANG ${ }^{1}$, FENG ZHU ${ }^{1}$, HUI JIANG ${ }^{1}$ and YU WANG ${ }^{2}$ \\ ${ }^{1}$ Collaborative Innovation Center for Petrochemical New Materials, Anhui Key Laboratory of Functional Coordination \\ Compounds, School of Chemistry and Chemical Engineering, Anqing Normal University, \\ Anqing 246011, People's Republic of China \\ ${ }^{2}$ School of Resource and Environmental Science, Anqing Normal University, Anqing 246011, People's Republic of China
}

MS received 13 April 2015; accepted 2 May 2016

\begin{abstract}
The water-soluble polymeric chemosensor poly(AM-GRBD) has been synthesized by precipitation copolymerization with the functional monomer, GRBD, which was made of $\mathrm{N}^{\prime \prime}$-(rhodamine B-yl) diethylenetriamine and glycidyl methacrylate (GMA) and a hydrophilic co-monomer acrylamide (AM). The chemical sensor behaved as a fluorescent and chromogenic sensor towards various heavy metal cations and transition metal cations; particularly, $\mathrm{Cr}^{3+}, \mathrm{Fe}^{3+}$ and $\mathrm{Hg}^{2+}$ ions in completely aqueous media. The fluorescence of poly(AM-GRBD) was enhanced by $\mathrm{Cr}^{3+}, \mathrm{Fe}^{3+}$ and $\mathrm{Hg}^{2+}$ metal ions. Moreover, during titration of $\mathrm{Cr}^{3+}, \mathrm{Hg}^{2+}$ or $\mathrm{Fe}^{3+}$ to the aqueous solution of poly(AM-GRBD), the visual colour changed from colourless to pink or brown yellow under visible light.
\end{abstract}

Keywords. Fluorescent sensor; water-soluble polymer; rhodamine B; diethylenetriamine; acrylamide.

\section{Introduction}

The development of fluorescent sensors for the detection of environmentally and biologically relevant heavy metal and transition metal cations, such as $\mathrm{Cr}^{3+}, \mathrm{Fe}^{3+}, \mathrm{Hg}^{2+}$, and so on [1-3], is currently of great interest because these metal ions are pollutants in environment or involved in a variety of fundamental biological processes in organisms [4-9]. A variety of fluorescent cation sensors have been developed based on small molecules as cation receptors [10-12]. Nevertheless, these materials have shown several problems such as low mechanical and thermal stability, weak chemical union with the metals, poor removal efficiency, high cost, etc. In contrast with small molecular sensors [13], it is well known that polymer-based systems have advantages over low-molecularweight system in terms of stability, easy handling and reuse. When the fluorescent probes were covalently bonded to the polymer chain, they generally show very similar effect as monomeric fluorophore $[14,15]$. The copolymers of traditional monomers with some polymerizable fluorescent units display intensive fluorescence. For many acrylic monomers bearing chromophore, Li et al [16] and Cui et al [17] found that the fluorescent intensity of the polymerizable fluorescent monomer is dramatically lower than those of its polymer or copolymer in the same chromophore concentration, due to the 'structural self-quenching effect' [18]. Moreover, the covalent bonding of the fluorophores to the polymer chain provided good stability to solvents and migration, improving their environmental behaviours [19]. Stomphorst et al [20,21] indicated that the use of polymer matrixes

*Author for correspondence (gengtongmou@aqtc.edu.cn) can avoid clustering of the dye molecules to aggregate the chromophores such as chlorophylls or porphyrins, often displayed in water and organic solvents. In the past decade, there is considerable interest in the field of chemosensor in the design of polymeric sensors for cation and anion recognition [22,23].

Although many polymers containing recognition chromophore are designed and investigated, most of them are applied in organic solution which limited their application in biological condition [18]. In order to be used as a matrix for fluorescent chemosensor purposes in aqueous solution, the polymer must be water-soluble [24]. Among the watersoluble polymer utilized, polyacrylamide (PAM) has been quite appropriate for the purpose, because it is water-soluble with attractive properties for applications in water-soluble polymeric sensors $[13,15,25,26]$.

Rhodamine dyes are widely used as fluorescent probes and sensors owing to their high absorption coefficient and broad fluorescence in the visible region of the electromagnetic spectrum, high fluorescence quantum yields and photostability after complexes with metal ions by activating a carbonyl group in a spirolactone or a spirolactam moiety [27-30]. The mechanism is based on the switch off/on of the spirocyclic moiety mediated by guests.

In general, spirolactam formation of rhodamine derivatives is non-fluorescent, whereas its ring-opened amide system by guests gives rise to a pink colour and strong fluorescence emission. Recently, rhodamine-based sensors for cations and other analytes have received ever-increasing interest in areas such as sensors for $\mathrm{Hg}^{2+}, \mathrm{Fe}^{3+}, \mathrm{Cr}^{3+}, \mathrm{NO}$ and $\mathrm{OCl}^{-}$ $[9,13,27,28,31,32]$. In this article, we design the functional monomer, GRBD, which is made of $\mathrm{N}^{\prime \prime}$-(rhodamine B-yl) 
diethylenetriamine and glycidyl methacrylate (GMA) and its copolymer poly(AM-GRBD) with the water-soluble monomer acrylamide (see scheme 1). The response of the copolymer to the presence of different metal cations in aqueous solutions has been investigated as well.

\section{Experimental}

\subsection{Instrumentation}

The ${ }^{1} \mathrm{H}$ NMR spectra were measured on a DRX 400 Bruker spectrometer (AVANCE AV 400, Bruker Corporation, Switzerland) at $298 \mathrm{~K}$ in $\mathrm{CDCl}_{3}$ or $\mathrm{D}_{2} \mathrm{O}$ with $\mathrm{TMS}$ as internal standard. FTIR spectra were recorded on a Nicolet Neus 8700 FTIR spectrophotometer (Thermo Scientific Instrument $\mathrm{Co}$. USA) with $\mathrm{KBr}$ compressing tablet. Elemental analyses $(\mathrm{C}, \mathrm{H}$ and $\mathrm{N})$ were carried out on a VarioELIII analyzer (Elementar Corporation, Germany) for the monomer GRBD. All pH measurements were made with a Model pHS-3C pH meter (Shanghai, China). Fluorescence spectra were acquired on a RF5301PC fluorescence spectrophotometer (Shimadzu Corporation, Japan). The viscosity average molecular weight $\left(M_{\eta}\right)$ was estimated for PAM and poly(AM-GRBD) from intrinsic viscosity of the polymer in aqueous solution at a constant temperature of $30^{\circ} \mathrm{C}$ with Ubbelohde viscometer $(\Phi=0.51 \mathrm{~mm})$.

\subsection{Material}

Rhodamine B, glycidyl methylacrylate (GMA) and 2,2'azo bis(2-methylpropionitrile) (AIBN, 98\%) were purchased from Sigma-Aldrich Trading Co. Ltd (Shanghai, China). Diethylenetriamine and natrium sulphuricum were purchased from Sinopharm Chemical Reagent Co. Ltd (Shanghai, China) and used without further purification.
Acrylamide (AM) was supplied by Aladdin Chemistry Co. Ltd (Shanghai, China); $\mathrm{N}_{2}$ gas, sulphuric acid, sodium hydrate and sodium chloride were obtained from commercial suppliers and all were analytically pure. Anhydrous methanol and ethanol, dichloromethane, chloroform, ethyl acetate, petroleum ether and tetrahydrofuran (THF) were obtained from commercial suppliers. Rhodamine B-yl diethylenetriamine (RBD) was prepared according to the literature method [33-38].

\subsection{Synthesis of monomer GRBD}

A quantity of $0.142 \mathrm{~g}(1.0 \mathrm{mmol})$ of GMA mixed with $10 \mathrm{ml}$ of trichloromethane was added dropwise from an addition funnel to $0.528 \mathrm{~g}$ (1.0 mmol) of RBD in $10 \mathrm{ml}$ of trichloromethane at $60^{\circ} \mathrm{C}$ for about $50 \mathrm{~min}$ under stirring. The mixture was refluxed for an additional $15 \mathrm{~h}$ after complete addition of GMA. The reactions were monitored by change of epoxide number or FT-IR. The obtained liquid was rotate and vacuum evaporated for removing the solvent to get a violet-red residue, which was purified by silica-gel column chromatography with ethyl acetate-petroleum ether (2:1, $\mathrm{v} / \mathrm{v}$ ) as eluent, affording $0.544 \mathrm{~g}$ of GRBD (yield: $81.15 \%$ ) [33,34]. FT-IR of GRBD (KBr), $v \mathrm{~cm}^{-1}: 3363.64\left(\mathrm{~s}, \nu_{-\mathrm{NH}}\right)$; $3084.95\left(\mathrm{~m}, v_{-\mathrm{C}=\mathrm{C}-\mathrm{H}}\right) ; 2966.46(\mathrm{~s}), 2933.54(\mathrm{~s}), 2872.10$ (s), $\left[v_{\mathrm{C}-\mathrm{H}(\mathrm{CH} 2, \mathrm{CH} 3)}\right] ; 1731.04 \quad\left(\mathrm{~s}, \quad v_{\mathrm{C}=\mathrm{O}},-\mathrm{CO}-\mathrm{O}-\right) ; 1673.98$ $\left(\mathrm{s}, \quad v_{\mathrm{C}=\mathrm{O}},-\underline{\mathrm{CO}}-\mathrm{NH}-\right) ; \mathrm{m} 1616.93\left(\mathrm{~s}, v_{\mathrm{ArC}=\mathrm{C}}\right) ; 1507.21$ $\left(\mathrm{s}, \delta_{\mathrm{N}-\mathrm{H}}\right), 1467.71\left(\mathrm{~m}, v_{\mathrm{ArC}=\mathrm{C}}\right), 1353.61\left(\mathrm{~m}, v_{\mathrm{ArC}=\mathrm{C}}\right), 1217.55$, $1110.03(\mathrm{C}-\mathrm{O}) .{ }^{1} \mathrm{H}$ NMR of GRBD $\left(400 \mathrm{MHz}, \mathrm{CDCl}_{3}\right), \delta$ : $0.969\left(\mathrm{~s}, \mathrm{H}_{2} \mathrm{C}=\mathrm{C}-\mathrm{CH}_{3}\right), 1.030-1.188\left(\mathrm{~s},-\mathrm{CH}_{2}-\mathrm{CH}_{3}\right), 1.869$ (s, HO-CH-C $\left.\underline{H}_{2}-\mathrm{NH}-\right) ; 2.398-2.732\left(-\mathrm{CH}_{2}-\mathrm{N} \underline{\mathrm{H}}-\mathrm{CH}_{2}-\right)$; 2.826 (- $\underline{\mathrm{CH}}-\mathrm{OH}) ; 3.108-3.117$ (d, $\mathrm{NH}_{2}-\mathrm{C}_{2}-\mathrm{C}_{2}-\mathrm{NH}-$ ); $3.412-3.36\left(\mathrm{COO}-\mathrm{CH}_{2}-\mathrm{CH}-\mathrm{OH}\right) ; 3.622-3.675\left(\mathrm{~s}, \mathrm{CH}_{3}-\right.$ $\left.\mathrm{C}_{2}-\mathrm{N}-\right) ; 4.488-4.567(\mathrm{~s},-\mathrm{CH}-\mathrm{O} \underline{\mathrm{H}}) ; 5.15\left(\mathrm{~d}, \underline{\mathrm{H}}_{2} \mathrm{C}=\mathrm{C}-\right.$ $\left.\mathrm{CH}_{3}\right) ; 5.645\left(\mathrm{~s},=\mathrm{CH}_{2}\right) ; 6.204-6.367(\mathrm{~m},-\Phi-\mathrm{H}) ; 7.021$
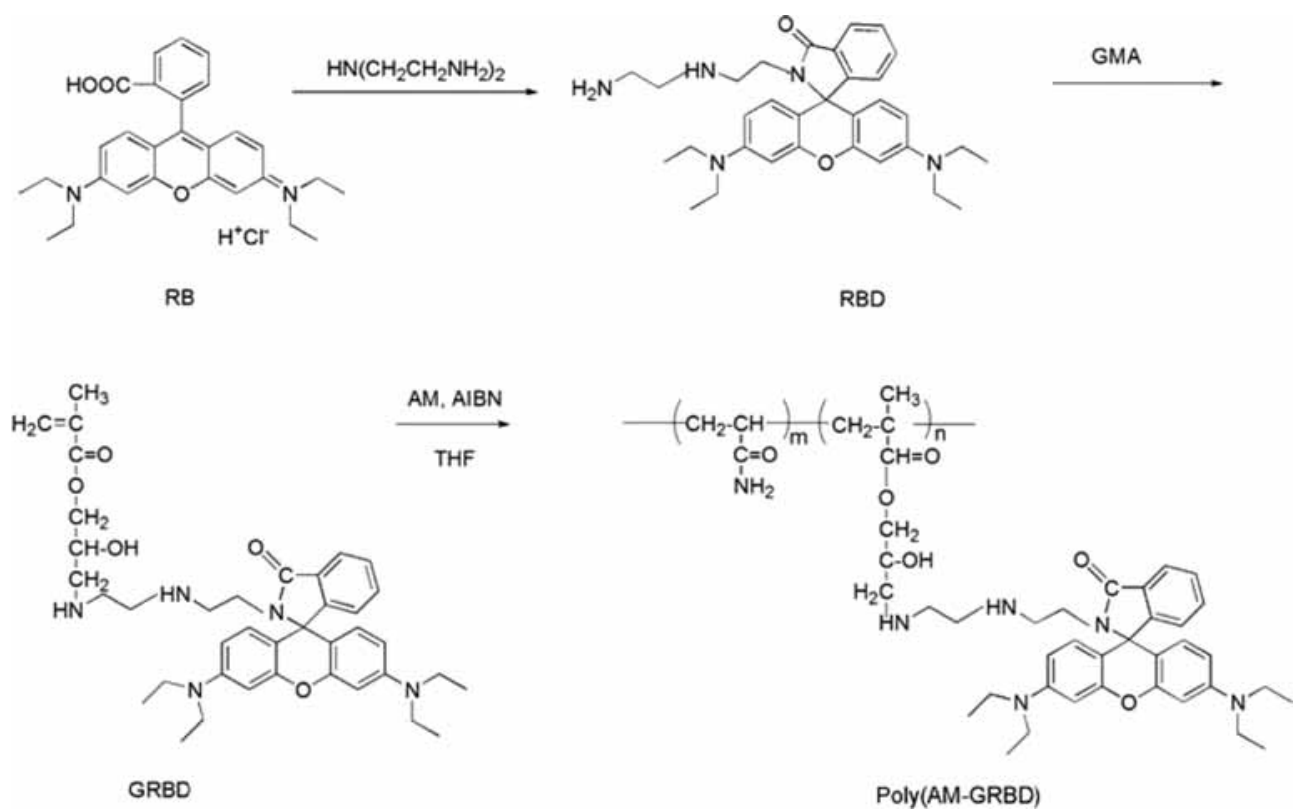

Scheme 1. Synthesis of poly(AM-GRBD). 
(s, -Ф-H); 7.370-7.409 (s, -Ф-H); 7.813 (s, -Ф-H). Anal. calc. for $\mathrm{C}_{39} \mathrm{H}_{51} \mathrm{~N}_{5} \mathrm{O}_{5}(\%)$ : C, 69.82; H, 7.74; N, 10.45 . Found (\%): C, 69.87; H, 7.87; N, 10.35.

\subsection{Synthesis of PAM and poly(AM-GRBD)}

A solution of AM (0.7108 g, $10.0 \mathrm{mmol})$ and AIBN (0.0657 g, $0.04 \mathrm{mmol}$ ) in $25 \mathrm{ml}$ of dry THF was introduced into a dry three-neck round-bottomed flask. The solution was deoxygenated by purging with purified $\mathrm{N}_{2}$. The three-neck round-bottomed flask was sealed and placed in a regulated thermostat bath at $65^{\circ} \mathrm{C}$ for $12 \mathrm{~h}$. The mixture was cooled to room temperature. The obtained white precipitate was collected by filtration, washed two times with chloroform $(5 \mathrm{ml} \times 2)$ and dried at $50^{\circ} \mathrm{C}$ under vacuum to a constant weight (0.6773 g, yield: $95.29 \%)$ [35-42].

The poly(AM-GRBD) was prepared by similar methods as the polymerization of AM. The recipes were as described. AM: $1.3962 \mathrm{~g}$ (19.6 mmol) and GRBD: $0.2679 \mathrm{~g}$ (0.4 mmol). The poly(AM-GRBD) was dissolved in double distilled water $(5 \mathrm{ml})$ and again precipitated into absolute ethyl alcohol. The above dissolution-precipitation cycle was repeated three times. The copolymers were purified with a Soxhlet extractor for $12 \mathrm{~h}$ with chloroform and absolute ethyl alcohol, respectively. The final products were dried at $50^{\circ} \mathrm{C}$ under vacuum to produce poly(AM-GRBD) as purple powders $(1.4544 \mathrm{~g}$, yield: $89.36 \%)$ [15,43-45]. FTIR $(\mathrm{KBr})$ of poly(AM-GRBD), $v \mathrm{~cm}^{-1}: 3394.36,3199.06$ $\left(-\mathrm{CONH}_{2}\right) ; 2929.15,1450.16\left(-\mathrm{CH}_{2}-\right) ; 2856.74(-\mathrm{CH}-)$; $1667.40(\mathrm{C}=\mathrm{O}) ; 1627.90,1518.18,1419.44(\mathrm{Ar}) ; 1121.06$ (C-O). ${ }^{1} \mathrm{H}$ NMR of poly(AM-GRBD) (400 MHz, $\left.\mathrm{D}_{2} \mathrm{O}\right)$, $\delta$ : $1.046-1.092\left(\mathrm{~m},-\mathrm{CH}_{3}\right) ; 1.593\left(\mathrm{~d},-\mathrm{CH}_{2}-\right) ; 1.682-1.736$ $\left(\mathrm{CHOH}-\mathrm{CH}_{2}-\mathrm{NH}-\right) ; \quad 1.394-1.408 \quad\left(-\mathrm{CH}_{3}\right) ; 2.158-2.176$ (m, -CH-); 2.277 (-NH- $\left.\underline{\mathrm{CH}}_{2}-\mathrm{CH}_{2}-\mathrm{NH}-\right) ; 2.394-2.406$ (-NH-); 3.467-3.488 (s, -N- $\left.\mathrm{CH}_{2}-\mathrm{CH}_{3}\right) ; 3.547$ (CH-OH); 3.689 (s, -NH-); 4.908 (m, $\left.-\mathrm{COO}-\mathrm{CH}_{2}-\mathrm{CHOH}\right) ; 5.976$ (s, -CH-OH); 6.133-6.226 (s, -Ф-H); 6.57-7.19 (m, Ф-H); 7.605-7.013 (s, $-\Phi-H)$.

\subsection{Measurement procedures}

The poly(AM-GRBD) stock solution $\left(1.00 \mathrm{mg} \mathrm{ml}^{-1}\right.$ ) was prepared in an aqueous solution. The $\mathrm{pH}$ was adjusted from 2.25 to 10.82 by the addition of $\mathrm{H}_{2} \mathrm{SO}_{4}$ or $\mathrm{NaOH}$ to the copolymer aqueous solution with a digital $\mathrm{pH}$ controller. The effects of the metal cations on the fluorescent intensity were examined by adding a few microlitre of the metal cations solution (the concentration of metal cations was $0.10 \mathrm{~mol}^{-1}$ ) to a known volume of the copolymer solution $(2.00 \mathrm{ml})$. The total volume of the addition metal cations solution was limited to $0.10 \mathrm{ml}$, so that the dilution of the copolymer solution remained insignificant. The metal ions are nitrate salts of $\mathrm{Ag}^{+}, \mathrm{Ba}^{2+}, \mathrm{Cd}^{2+}, \mathrm{Co}^{2+}, \mathrm{Cr}^{3+}, \mathrm{Cu}^{2+}, \mathrm{Fe}^{2+}, \mathrm{Fe}^{3+}, \mathrm{Hg}^{2+}$, $\mathrm{K}^{+}, \mathrm{Mg}^{2+}, \mathrm{Mn}^{2+}, \mathrm{Na}^{+}, \mathrm{Ni}^{2+}, \mathrm{Pb}^{2+}$ and $\mathrm{Zn}^{2+}$, whose solutions were prepared in distilled water. For all fluorescent measurements, excitation wavelength was $500 \mathrm{~nm}$ with the emission recorded over the wavelength range of 520-650 nm
[46]. The detection limit was calculated using the following equation:

Detection limit $=3 S / \rho$,

where $S$ is the standard deviation of blank measurements and $\rho$ the slope between intensity vs. sample concentration [27,46-48]. The viscosity average molecular weight $\left(M_{\eta}\right)$ of PAM and poly(AM-GRBD) was estimated from intrinsic viscosity of the polymers in distilled water at a constant temperature of $30^{\circ} \mathrm{C}$, using the Mark-Houwink-Sakurada (MHS) equation [49]:

$$
[\eta]=k M_{\eta}^{\alpha}\left(k=9.33 \times 10^{-3}, \alpha=0.75\right) .
$$

\section{Results and discussion}

\subsection{Molecular design and syntheses of sensors $\operatorname{poly}(A M-G R B D)$}

Based on the selective host-guest design for metal cation sensors, we utilized the glycidyl methacrylate-rhodamine-yl diethylenetriamine ligand (GRBD) as a host, which could provide seven binding sites to metal cation via favourable electrostatic interactions of metal cations to the nitrogen and oxygen atoms $[34,35,50]$. The nitrogen in the diethylenetriamine linker and the carbonyl oxygen can provide binding unit for metal cations $[51,52]$. It was expected that the copolymer poly(AM-GRBD) would sense more than one metal ions.

The synthetic strategy of the monomer and copolymers is shown in scheme 1 . The sensor was readily synthesized by employing shorter synthetic routes and economy of starting materials [50]. First, RBD was facilely synthesized through amidation of diethylenetriamine with rhodamine B in ethanol, which can be prepared in high yield [33,52]. Then, the polymerizable monomer GRBD was prepared by ringopening reaction between $\mathrm{RBD}$ and the epoxide functional group of GMA [46]. Finally, the water-soluble copolymer poly(AM-GRBD) was prepared by conventional free radical precipitation polymerization of GRBD with AM. As is well known, PAM has the advantage of excellent water-solubility, so AM is quite appropriate to be selected as monomer [46].

The structures of the monomer GRBD and copolymer poly(AM-GRBD) were confirmed by FTIR and ${ }^{1} \mathrm{H}$ NMR. The characteristic FTIR spectra of the polymeric sensor showed aromatic rhodamine peaks (1622 and $1510 \mathrm{~cm}^{-1}$ ) and acid amides peak (3394-3199 $\left.\mathrm{cm}^{-1}\right)$, and the wide absorption band at $3480 \mathrm{~cm}^{-1}$ was indicative of the $-\mathrm{NH}$ and $-\mathrm{OH}$ functional groups. The prominent peak at $1667 \mathrm{~cm}^{-1}$ was attributed to the stretching vibration of an amide carbonyl [46]. Typical ${ }^{1} \mathrm{H}$ NMR spectra of the poly(AM-GRBD) showed the characteristic signals of $-\mathrm{CH}_{2}$ and $-\mathrm{CH}$ groups in the region of 1.0-2.1 and 2.2-2.6 ppm and aromatic protons at $7.8-5.5 \mathrm{ppm}$, respectively. The characteristic NMR signals corresponding to the vinyl groups of the monomer (d(H) 5.77 and 5.32) disappeared completely in the copolymer, and the signals corresponding to the xanthene and benzene 
rings of GRBD $\left(\mathrm{d}(\mathrm{H})\right.$ 6.0-8.0) appeared in the ${ }^{1} \mathrm{H}$ NMR spectra of poly(AM-GRBD). This observation confirmed that the hydrophobic functional monomer GRBD had been successfully incorporated into the polymer [9]. The average molecular weights of PAM and poly(AM-GRBD) were 5.72 $\times 10^{4}$ and $6.18 \times 10^{3} \mathrm{~g} \mathrm{~mol}^{-1}$, respectively, which were designed to be reasonably low to ensure the water solubility of the material [9].

\subsection{Effects of $\mathrm{pH}$ on fluorescent intensity of poly $(A M-G R B D)$}

The chemosensor containing spirolactam ring and nitrogen donors was highly sensitive to environmental $\mathrm{pH}$, as the protonation degree of nitrogen was strongly dependent on the $\mathrm{pH}$ [52]; hence, for practical applicability of the poly(AMGRBD), a proper $\mathrm{pH}$ range of 2.25-10.82 was determined. Figure 1 shows variations of the fluorescence intensity of poly(AM-GRBD) $\left(C_{\mathrm{p}}=0.2 \mathrm{mg} \mathrm{ml}^{-1}, \lambda_{\mathrm{ex}}=500 \mathrm{~nm}\right)$ with $\mathrm{pH}$ in the absence of the metal ion in aqueous solution [53]. The poly(AM-GRBD) had a weak fluorescence emission within the $\mathrm{pH}$ range 5.43-10.82 and the solution colour could hardly be observed due to the presence of the ring-closed spirolactam structure. With the increase in solution acidity, the fluorescence of poly(AM-GRBD) in aqueous solution was gradually enhanced along with clear colour changes from colourless to pink, which implied that the spirolactam ring of poly(AM-GRBD) was opened up due to protonation. Considering that higher $\mathrm{pH}$ range could lead to hydrolysis for transition metal ions, the proper $\mathrm{pH}$ span for poly(AM-GRBD) to sense metal ions in aqueous solution was selected to be under near-neutral $\mathrm{pH}$ conditions, which was a physiological $\mathrm{pH}$ value too $[52,54]$.

\subsection{Sensitivity of poly(AM-GRBD)}

Concentration effects of $\mathrm{Cr}^{3+}, \mathrm{Fe}^{3+}$ and $\mathrm{Hg}^{2+}$ ions on the emission spectra of the poly(AM-GRBD) $\left(0.2 \mathrm{mg} \mathrm{ml}^{-1}\right.$,

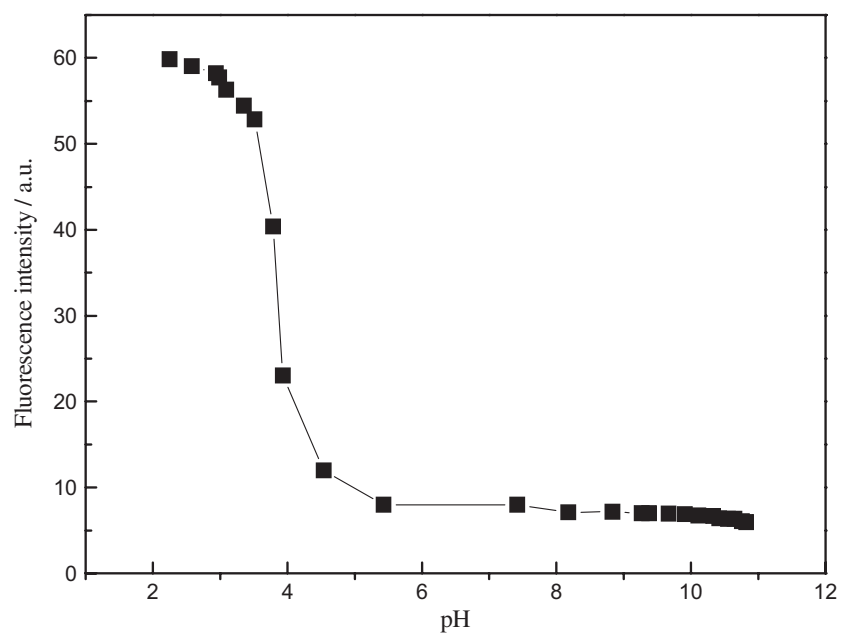

Figure 1. Fluorescent intensity of poly(AM-GRBD) in aqueous solution $\left(C_{\mathrm{p}}=0.2 \mathrm{mg} \mathrm{m1}^{-1}, \lambda_{\mathrm{ex}}=500 \mathrm{~nm}\right)$ at different $\mathrm{pH}$. $\lambda_{\text {ex }}=500 \mathrm{~nm}$ ) are given in figure $2 \mathrm{a}-\mathrm{c}$, respectively. Inset of figure 2 shows the relationship of relative fluorescent intensity $\left(I / I_{0}\right)$ of poly(AM-GRBD) in aqueous solution with ion concentration of $\mathrm{Cr}^{3+}, \mathrm{Fe}^{3+}$ and $\mathrm{Hg}^{2+}$. Here $I$ is the fluorescence emission intensity of poly(AM-GRBD) actually
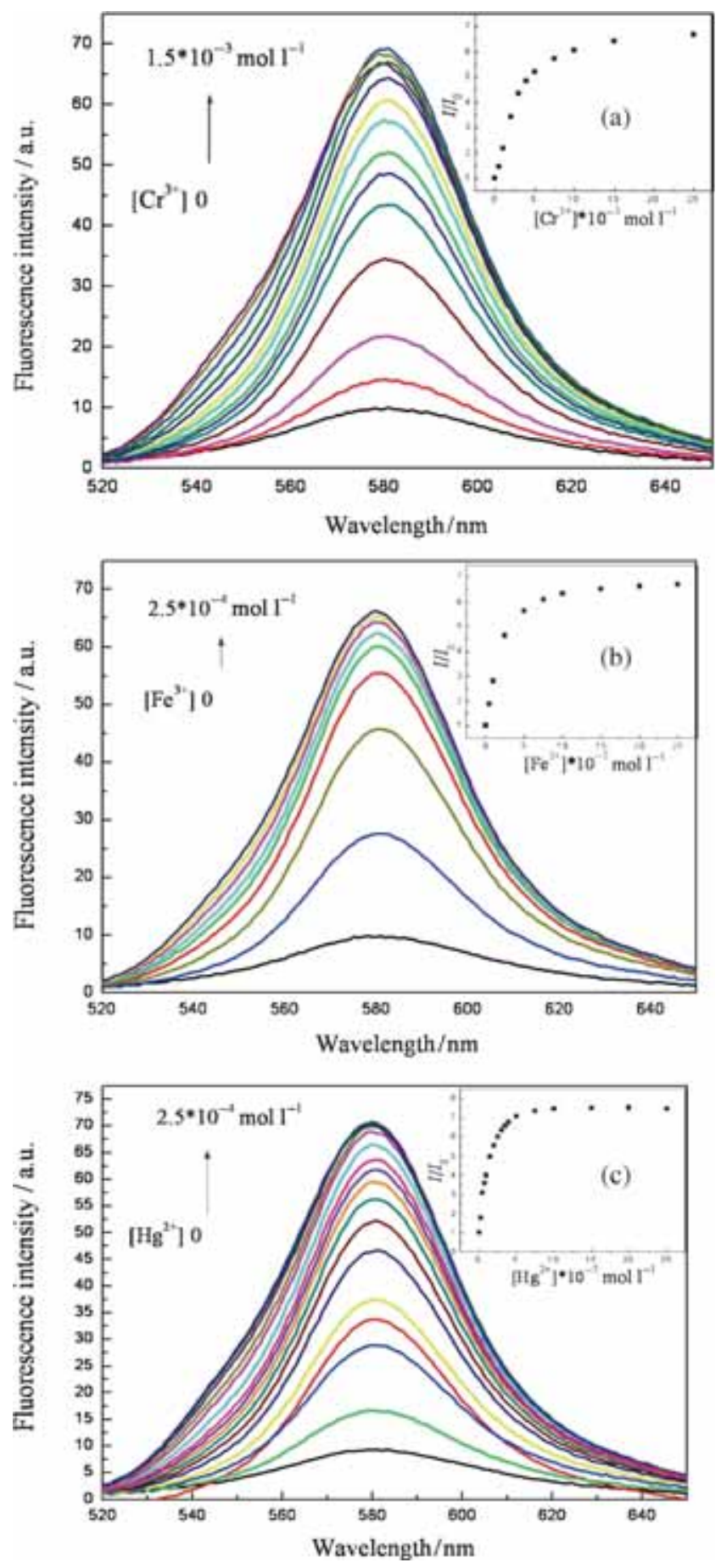

Figure 2. Fluorescence spectra of poly(AM-GRBD) $\left(C_{\mathrm{p}}=0.2\right.$ $\left.\mathrm{mg} \mathrm{ml}^{-1}, \lambda_{\mathrm{ex}}=500 \mathrm{~nm}\right)$ in the presence of increasing concentrations of (a) $\mathrm{Cr}^{3+}\left(0\right.$ to $\left.1.5 \times 10^{-3} \mathrm{~mol} \mathrm{l}^{-1}\right)$, (b) $\mathrm{Fe}^{3+}(0$ to $2.5 \times$ $\left.10^{-4} \mathrm{~mol} \mathrm{l}^{-1}\right)$ and (c) $\mathrm{Hg}^{2+}\left(0\right.$ to $\left.2.5 \times 10^{-4} \mathrm{~mol} \mathrm{l}^{-1}\right)$. Inset: the relative fluorescent intensity $\left(I / I_{0}\right)$ changes of poly(AM-GRBD) upon gradual addition of $\mathrm{Cr}^{3+}, \mathrm{Fe}^{3+}$ and $\mathrm{Hg}^{2+}$. 


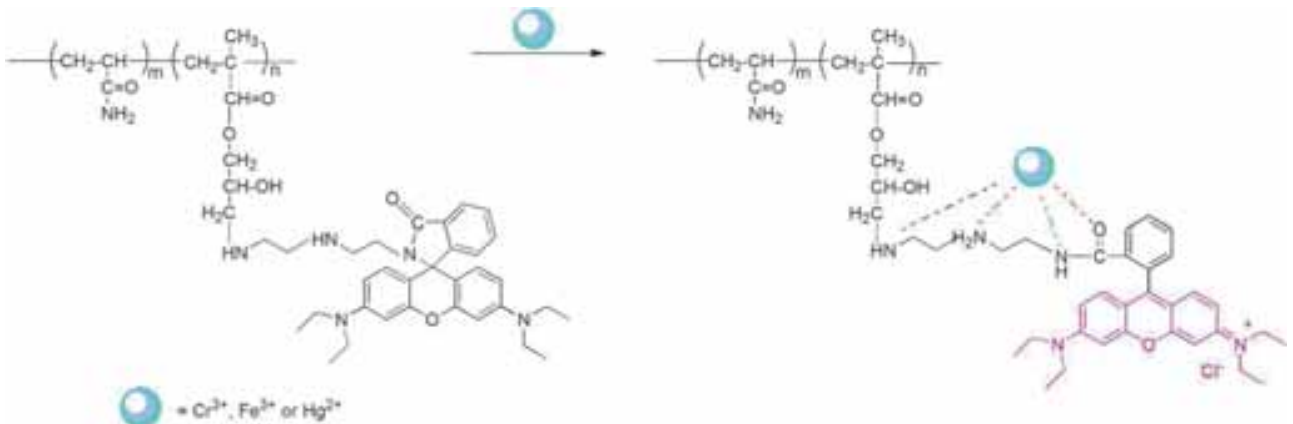

Scheme 2. Possible mechanism of $\mathrm{Cr}^{3+}, \mathrm{Fe}^{3+}$ - and $\mathrm{Hg}^{2+}$-induced ring opening of rhodamine moiety on poly(AM-GRBD).

Table 1. Equation of $I / I_{0}$ of poly(AM-ARBD) to the concentrations of $\mathrm{Cr}^{3+}, \mathrm{Fe}^{3+}$ and $\mathrm{Hg}^{2+}$ cations.

\begin{tabular}{|c|c|c|c|c|c|}
\hline Metal cations & Equation & $\begin{array}{c}\text { Regression } \\
\text { coefficient }(R)\end{array}$ & $\begin{array}{l}\text { Concentration range of } \\
\text { metal cations }\left(\mathrm{mol} \mathrm{l}^{-1}\right)\end{array}$ & $\begin{array}{l}\text { Detection limit } \\
\quad\left(\mathrm{mol} \mathrm{l}^{-1}\right)\end{array}$ & $\begin{array}{l}\text { Equation } \\
\text { number }\end{array}$ \\
\hline $\mathrm{Cr}^{3+}$ & $I / I_{0}=0.9907+1.1476 \times 10^{5}\left[\mathrm{Cr}^{3+}\right]$ & 0.9971 & 0 to $3 \times 10^{-5}$ & $2.61 \times 10^{-11}$ & 1 \\
\hline $\mathrm{Fe}^{3+}$ & $I / I_{0}=1.1366+1.4405 \times 10^{5}\left[\mathrm{Fe}^{3+}\right]$ & 0.9941 & 0 to $2.5 \times 10^{-5}$ & $4.16 \times 10^{-11}$ & 2 \\
\hline $\mathrm{Hg}^{2+}$ & $I / I_{0}=0.1001+3.6339 \times 10^{5}\left[\mathrm{Hg}^{2+}\right]$ & 0.9874 & 0 to $7.5 \times 10^{-6}$ & $8.25 \times 10^{-12}$ & 3 \\
\hline $\mathrm{Hg}^{2+}$ & $I / I_{0}=3.8887+7.9764 \times 10^{4}\left[\mathrm{Hg}^{2+}\right]$ & 0.9858 & $1.5 \times 10^{-5}$ to $3.5 \times 10^{-5}$ & $3.76 \times 10^{-11}$ & 4 \\
\hline
\end{tabular}

measured at a given metal concentration, $I_{0}$ is the fluorescence emission intensity of the poly(AM-GRBD) with free ions, and $\left[\mathrm{Cr}^{3+}\right],\left[\mathrm{Fe}^{3+}\right]$ and $\left[\mathrm{Hg}^{2+}\right]$ represented the concentration of $\mathrm{Cr}^{3+}, \mathrm{Fe}^{3+}$ and $\mathrm{Hg}^{2+}$ added. When no metal ion was added to the solution of poly(AM-GRBD), only weak fluorescence signal in the range from 520 to $650 \mathrm{~nm}$ could be observed, because the spirocyclic form of rhodamine prevailed. However, upon treating with $\mathrm{Cr}^{3+}, \mathrm{Fe}^{3+}$ or $\mathrm{Hg}^{2+}$, significant enhancement of $I / I_{0}$ emerged quickly, which were reasonably assigned to the delocalized xanthene tautomer of the rhodamine group [51,55-61] and the colour changes from colourless to pink $\left(\mathrm{Cr}^{3+}\right.$ and $\mathrm{Hg}^{2+}$ ) or brown-yellow $\left(\mathrm{Fe}^{3+}\right)$ were observed simultaneously [57,59]. Further addition of $\mathrm{Cr}^{3+}, \mathrm{Fe}^{3+}$ or $\mathrm{Hg}^{2+}$ cations hardly had any effect upon the relative fluorescence intensity that was indicative of an entirely fluorescent complex formed between poly(AMGRBD) and $\mathrm{Cr}^{3+}, \mathrm{Fe}^{3+}$ or $\mathrm{Hg}^{2+}$ cations, respectively [62], and about 6.89-, 6.76- or 7.46-fold enhancement in the fluorescent intensity was noted [46]. The possible mechanism was described as shown in scheme 2. The GRBD units of poly(AM-GRBD) containing carbonyl (-CO-), imino groups $(-\mathrm{HN}-)$ and lactam could selectively chelate with metal ions by using $\mathrm{N}$ of imino and $\mathrm{O}$ atoms in structure to form more stable pentabasic or heptabasic rings. The spirolactam ringclosed form could be transformed to ring-opened amide form with high fluorescent caused by conjugation enhancement [63,64].

Supplementary figure S5a-c shows the plots of the emission intensity of poly(AM-GRBD) $v s$. the concentration of added $\mathrm{Cr}^{3+}, \mathrm{Fe}^{3+}$ and $\mathrm{Hg}^{2+}$ cations, and a good linearity relationship was obtained in certain range and could be expressed by the following equations (1-4) of the calibration line (table 1) $[15,46]$. The detection limit was found to be $10^{-11}$ to $10^{-12} \mathrm{~mol}^{-1}$ (calculated as three times standard

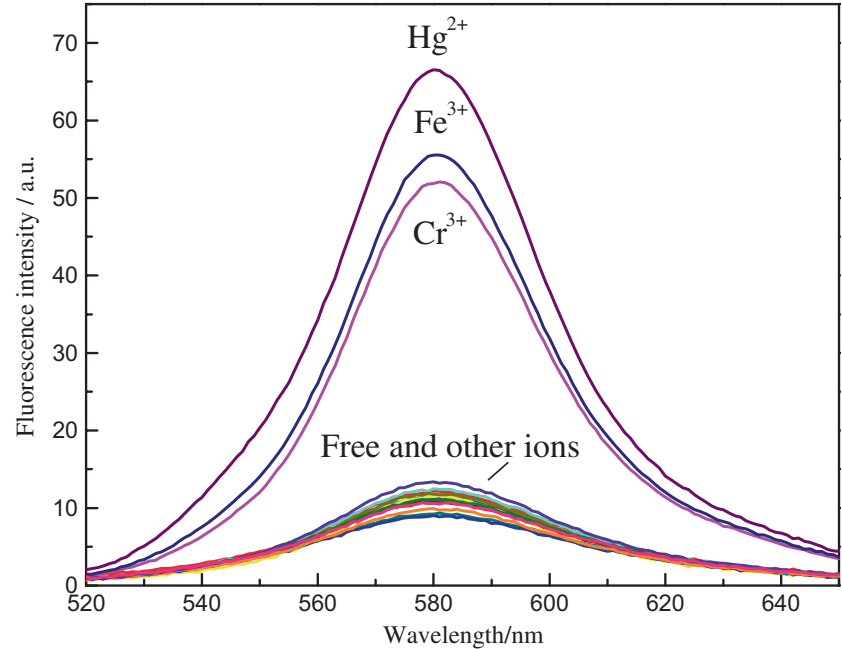

Figure 3. Fluorescence spectra of poly(AM-GRBD) $\left(C_{\mathrm{p}}=0.2\right.$ $\mathrm{mg} \mathrm{ml}^{-1}$ ) upon addition of $5.0 \times 10^{-5} \mathrm{~mol} \mathrm{l}^{-1}$ of diverse metal cations.

deviation of blank solution). Therefore, poly(AM-GRBD) was sensitive enough to detect $\mathrm{Cr}^{3+}, \mathrm{Fe}^{3+}$ and $\mathrm{Hg}^{2+}$ cations in complete water media [46].

\subsection{Selectivity and competitiveness of poly(AM-GRBD)}

The influences of various metal cations $\left(5.0 \times 10^{-5} \mathrm{~mol} \mathrm{l}^{-1}\right)$ on the relative luorescent intensity $\left(I / I_{0}\right)$ of the poly(AMGRBD) were investigated in neutral aqueous solution (figure 3). The poly(AM-GRBD) had no obvious response for fluorescence spectra upon additions of $\mathrm{Ag}^{+}, \mathrm{Ba}^{2+}, \mathrm{Cd}^{2+}, \mathrm{Co}^{2+}$, $\mathrm{Cu}^{2+}, \mathrm{Fe}^{2+}, \mathrm{K}^{+}, \mathrm{Na}^{+}, \mathrm{Ni}^{2+}, \mathrm{Mg}^{2+}, \mathrm{Mn}^{2+}, \mathrm{Pb}^{2+}$ and $\mathrm{Zn}^{2+}$, respectively, but had great fluorescence enhancement for 


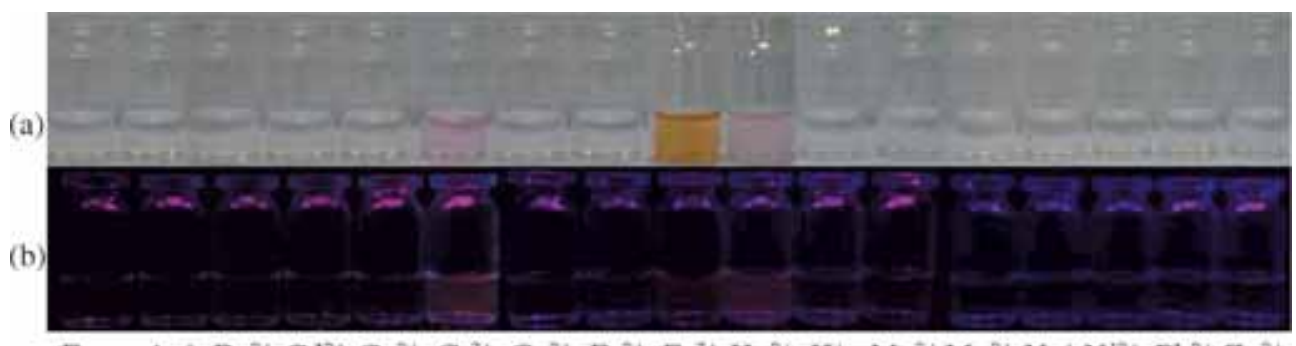

Free $\mathrm{Ag}^{+} \mathrm{Ba}^{2+} \mathrm{Cd}^{2+} \mathrm{Co}^{2+} \mathrm{Cr}^{3+} \mathrm{Cu}^{2+} \mathrm{Fe}^{2+} \mathrm{Fe}^{3+} \mathrm{Hg}^{2+} \mathrm{K}^{+} \mathrm{Mg}^{2+} \mathrm{Mn}^{2+} \mathrm{Na}^{+} \mathrm{Ni}^{2+} \mathrm{Pb}^{2+} \mathrm{Zn}^{2+}$

Figure 4. Photographs recorded under (a) visible light and (b) UV light at $365 \mathrm{~nm}$ for aqueous solutions of poly(AM-GRBD) $\left(0.2 \mathrm{mg} \mathrm{ml}^{-1}\right)$ in the presence of different metal ions $\left(2.5 \times 10^{-5}\right.$ $\left.\operatorname{mol~} 1^{-1}\right)$.

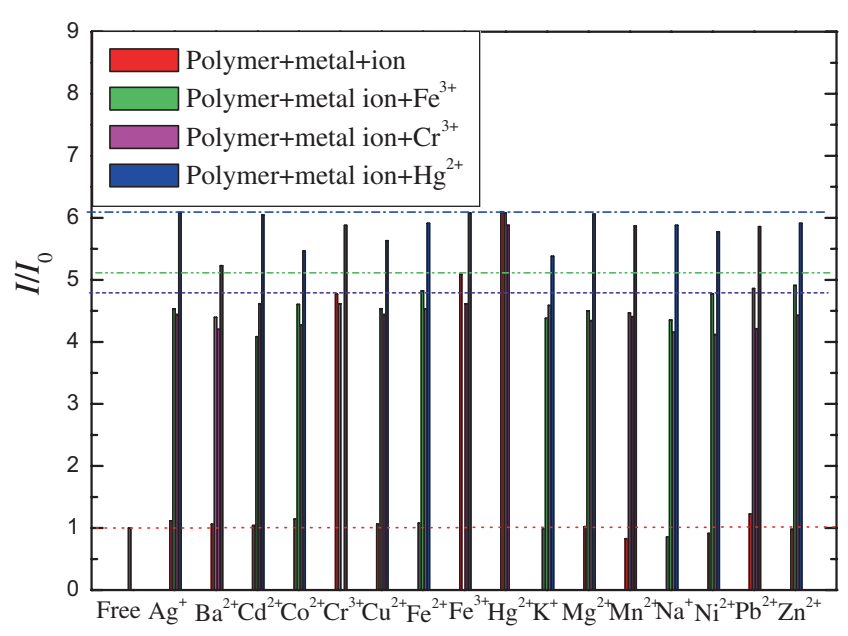

Figure 5. Selectivity of poly(AM-ARBD) $\left(C_{\mathrm{p}}=0.2 \mathrm{mg} \mathrm{ml}^{-1}\right)$ for $\mathrm{Cr}^{3+}, \mathrm{Fe}^{3+}$ and $\mathrm{Hg}^{2+}$ in the presence of other metal ions $(2.5$ $\times 10^{-5} \mathrm{~mol} \mathrm{l}^{-1}$ ) in neutral aqueous solution, red bars represent polymer + ion. Green, magenta or blue bars represent the subsequent addition of $\mathrm{Fe}^{3+}, \mathrm{Cr}^{3+}$ or $\mathrm{Hg}^{2+}\left(2.5 \times 10^{-5} \mathrm{~mol} \mathrm{l}^{-1}\right)$ to the solution, respectively.

$\mathrm{Cr}^{3+}, \mathrm{Fe}^{3+}$ and $\mathrm{Hg}^{2+}[19,62,65]$. The selectivity for $\mathrm{Cr}^{3+}$, $\mathrm{Fe}^{3+}$ and $\mathrm{Hg}^{2+}$ was probably due to the cooperation of several combined influences, such as the suitable coordination geometry, the proper radius and charge density of the $\mathrm{Cr}^{3+}$, $\mathrm{Fe}^{3+}$ and $\mathrm{Hg}^{2+}$ ions, and the amide deprotonation ability of $\mathrm{Cr}^{3+}, \mathrm{Fe}^{3+}$ and $\mathrm{Hg}^{2+}$ [46] (see scheme 2).

The colour and fluorescence changes of poly(AM-GRBD) on the addition of various cations are shown in figure 4 . Upon addition of $\mathrm{Cr}^{3+}, \mathrm{Fe}^{3+}$ or $\mathrm{Hg}^{2+}$, a visible colour change occurred from colourless to pale pink $\left(\mathrm{Cr}^{3+}\right.$ and $\left.\mathrm{Hg}^{2+}\right)$ or brown-yellow $\left(\mathrm{Fe}^{3+}\right)$ under visible light (figure 4, top). Under UV light at $365 \mathrm{~nm}$, the poly(AM-GRBD) in the presence of $\mathrm{Cr}^{3+}, \mathrm{Fe}^{3+}$ and $\mathrm{Hg}^{2+}$ emitted orange red fluorescence (figure 4, bottom) $[9,13,43,46,66-68]$.

The competition experiments were also carried out by adding $\mathrm{Cr}^{3+}, \mathrm{Fe}^{3+}$ or $\mathrm{Hg}^{2+}$ into the solution of poly(AMGRBD) $\left(0.2 \mathrm{mg} \mathrm{ml}^{-1}\right.$, excited at $\left.500 \mathrm{~nm}\right)$ in the presence of other metal ions $\left(2.5 \times 10^{-4} \mathrm{~mol} \mathrm{l}^{-1}\right)$ as shown in figure 5 . The results indicated that the sensing of $\mathrm{Cr}^{3+}, \mathrm{Fe}^{3+}$ or $\mathrm{Hg}^{2+}$ by poly(AM-GRBD) was hardly affected by these common interfering ions $[13,46]$.

\section{Conclusions}

A functional monomer bearing a rhodamine $\mathrm{B}$ derivative, GRBD, which was made of $\mathrm{N}^{\prime \prime}$-(rhodamine B-yl) diethylenetriamine and GMA group, was synthesized in this work. The radical precipitation copolymerization of the new monomeric fluorophore with the hydrophilic co-monomer AM was carried out. By means of fluorescence spectroscopy, we studied the sensibility and selectivity of poly(AM-GRBD) for metal cations in completely aqueous solution. The results showed that poly(AM-GRBD) was an efficient 'off-on' switcher for $\mathrm{Cr}^{3+}, \mathrm{Fe}^{3+}$ and $\mathrm{Hg}^{2+}$ metal ions. The titration of $\mathrm{Cr}^{3+}, \mathrm{Hg}^{2+}$ or $\mathrm{Fe}^{3+}$ to the aqueous solution of poly(AM-GRBD) led to the visual colour changes from colourless to pale pink or brown orange.

\section{Electronic Supplementary Material}

Supplementary material pertaining to this article is available on the Bulletin of Materials Science website (www.ias.ac.in/ matersci).

\section{Acknowledgement}

We acknowledge financial support from the National Natural Science Foundation of China (under Grant no. 21307002).

\section{References}

[1] Wang S and Chang Y T 2006 J. Am. Chem. Soc. 3210380

[2] Ojida A, Nonaka H, Miyahara Y, Tamaru S I, Sada K and Hamachi I 2006 Angew. Chem. Int. Ed. 455518

[3] Baruah M, Qin W, Vallée R A, Beljonne D, Rohand T, Dehaen W and Boens N 2005 Org. Lett. 204377

[4] Xu Z C, Xiao Y X, Qian X H, Cui J N and Cui D W 2005 Org. Lett. 7889

[5] Majzoub A E, Cadiou C, Olivier I D, Tinant B and Chuburu F 2011 Inorg. Chem. 504029

[6] Sarkar M, Banthia S and Samanta A 2006 Tetrahedron Lett. 477575

[7] Jung H S, Kwon P S, Lee J W, Kim J I, Hong C S, Kim J W, Yan S H, Lee J Y, Lee J H, Joo T and Kim J S 2009 J. Am. Chem. Soc. 52008 
[8] Fan L J and Jones W E 2006 J. Am. Chem. Soc. 1286784

[9] Wang Y, Wu H Q, Luo J and Liu X Y 2012 React. Funct. Polym. 72169

[10] Silva A P, Gunatatne H Q N, Gunnlauggson T, Huxley A J M, McCoy C P, Radmancher J T and Rice T E 1997 Chem. Rev. 971515

[11] Basheer M C, Alex S, Thomas K G, Suresh C H and Das S 2006 Tetrahedron 62605

[12] Ramachamdram B, Sankaran N B, Karmakar R, Saha S and Samanta A 2000 Tetrahedron 567041

[13] Noi N, Chatthai K, Weerapol S, Banchob W, Buncha P and Thawatchai T 2013 Polym. Chem. 43039

[14] Rurack K 2001 Spectrochem. Acta Part A 572161

[15] Wang B Y, Guan X L, Hu Y L and Su Z X 2008 J. Polym. Res. 15427

[16] Li F M, Ga Q Y, Wang L and Zhang J X 1997 J. Polym. Sci. Part A: Polym. Chem. 351087

[17] Cui Y C, Liu C Y and Gao Q Y 2000 Polym. Adv. Technol. 11 172

[18] Liu Y H, Meng L Z, Lu X J, Zhang L F and He Y B 2008 Polym. Adv. Technol. 19137

[19] Wang B Y, Liu X Y, Ding S L and Su Z X 2011 J. Polym. Res. 181315

[20] Stomphorst R G, van der Zwan G, van Zandvoort M A M J, Sieval A B, Zuilhof H, Vergeldt F J and Schaafsma T J 2001 J. Phys. Chem. A 1054235

[21] Wang B Y, Guan X L, Hu Y L and Su Z X 2007 Polym. Adv. Technol. 18529

[22] Huang H M, Wang K M, Tan W H, An D L and Yan X H 2004 Angew. Chem. Int. Ed. 435635

[23] Tang Y L, He F and Yu M H 2006 Macromol. Rapid. Commun. 27389

[24] Serrano B, Baselga J and Piérol I F 2002 Polym. J. 34905

[25] Kim S R, Yuk S H and John M S 1997 Eur. Polym. J. 331009

[26] Risbud M V and Bhonde R R 2000 Drug. Deliv. 769

[27] Chen X Q, Pradhan T, Wang F, Kim J S and Yoon J 2012 Chem. Rev. 1121910

[28] Antonio B, Estefanía D P, Enrique G E, Claudia G and Fernando P 2014 Coord. Chem. Rev. 260156

[29] Kim H N, Guo Z, Zhu W, Yoon J and Tian H 2011 Chem. Soc. Rev. 4079

[30] Beija M, Afonso C A M and Martinho J M G 2009 Chem. Soc. Rev. 382410

[31] Kim H N, Lee M H, Kim H J, Kim J S and Yoon J 2008 Chem. Soc. Rev. 371465

[32] Lee S, Anand H P and Schanze K S 2013 Macromol. Rapid Commun. 34791

[33] Xie P H, Guo F Q, Yang S, Yao D H, Yang G Y and Xie L X 2014 J. Fluoresc. 24473

[34] Jua H, Lee M H, Kim J, Kim J S and Kim J 2011 Talanta 83 1359

[35] Lee M H, Wu J S, Lee J W, Jung J H and Kim J S 2007 Org. Lett. 92501

[36] Lee M H, Kim H J, Yoon S, Park N and Kim J S 2008 Org. Lett. 10213
[37] Chai M M, Zhang D, Wang M, Hong H J, Ye Y and Zhao Y F 2012 Sens. Actuators B Chem. 174231

[38] Xiang Y and Tong A J 2006 Org. Lett. 81549

[39] Liu T, Joseph M D S and Roberts G W 2006 Polymer 474276

[40] Liu T, Garner P, Desimone J M et al 2006 Macromol. 396489

[41] Bunyakan C and Hunkeler D 1999 Polymer 406213

[42] Bunyakan C, Armanet L and Hunkeler D 1999 Polymer 40 6225

[43] Geng T M, Huang R Y and Wu D Y 2014 RSC Adv. 8646332

[44] Geng T M, Wu D Y and Huang W 2015 J. Polym. Res. 2240

[45] Geng T M, Wang X, Jiang H, Song W, Ni R F, Chen J and Wang Y 2016 J. Fluoresc. doi:10.1007/s10895-016-1785-4

[46] Luo J, Jiang S S, Qin S H, Wu H Q, Wang Y, Jiang J Q and Liu X Y 2011 Sens. Actuators B Chem. 1601191

[47] Zhou Z G, Yu M X, Yang H, Huang K W, Li F, Yi T Y and Huang C H 2008 Chem. Commun. 293387

[48] Kumar K S, Ramakrishnappa T, Balakrishna R G and Pandurangappa M 2014 J. Fluoresc. 2467

[49] Hill A, Candau F and Selb J 1993 Macromol. 264521

[50] Wanichacheva N, Praikaew P, Suwanich T and Sukrat K 2014 Spectrochim. Acta A 118908

[51] Mao J, Wang L N, Dou W, Tang X L, Yan Y and Liu W S 2007 Org. Lett. 94567

[52] Chereddy N R, Suman K, Korrapati P S, Thennarasu S and Mandal A B 2012 Dyes Pigm. 95606

[53] Wang X M, Iqbal M, Huskens J and Verboom W 2012 Int. J. Mol. Sci. 1316822

[54] Anindita S, Sujit S P, Partha B and Roy S 2012 J. Fluoresc. 22443

[55] He G J, Zhang X L, He C, Zhao X W and Duan C Y 2010 Tetrahedron 669762

[56] Yang Z, She M Y, Yin B, Cui J H, Zhang Y Z, Sun W, Li J L and Shi Z 2012 J. Org. Chem. 771143

[57] Ko S K, Yang Y K, Tae J S and Shin I J 2006 J. Am. Chem. Soc. 12814150

[58] She M Y, Yang Z, Yin B, Zhang J, Gu J, Yin W T, Li J L, Zhao G F and Shi Z 2012 Dyes Pigm. 921337

[59] Chatterjee A, Santra M, Won N, Kim S, Kim J K, Kim S B and Ahn K H 2009 J. Am. Chem. Soc. 1312040

[60] Zhang X L, Xiao Y and Qian X H 2008 Angew. Chem. Int. Ed. 478025

[61] Grabchev I, Dumas S and Chovelon J M 2008 Polym. Adv. Technol. 19316

[62] Li N J, Xu Q F, Xia X W, Wang L H, Lu J M and Wen X W 2009 Mater. Chem. Phys. 114339

[63] Tang R R, Lei K, Chen K, Zhao H and Chen J W $2011 \mathrm{~J}$. Fluoresc. 21141

[64] Duan Y L, Shi Y G, Chen J H, Wu X H, Wang G K, Zhou Y and Zhang J F 2012 Tetrahedron Lett. 536544

[65] Kaya İ and Kamac1 M 2013 J. Fluoresc. 1115

[66] Gao W, Yang Y T, Huo F J, Yin C X, Xu M, Zhang Y B, Chao J B, Jin S and Zhang S P 2014 Sens. Actuators B Chem. 193 294

[67] Song J H, Huai M X, Wang C C, Xu Z H, Zhao Y F and Ye Y 2015 Spectrochim. Acta Part A 139549

[68] Hu Z Q, Du M, Zhang L F, Guo F Y, Liu M D and Li M 2014 Sens. Actuators B Chem. 192439 